\title{
Trends and patterns of hormonal contraceptive prescribing for adolescents in primary care in the UK
}

\author{
Asia N Rashed, ${ }^{1}$ Yingfen Hsia, ${ }^{2}$ Lynda Wilton, ${ }^{3}$ May Ziller, ${ }^{4}$ Karel Kostev, ${ }^{5}$ \\ Stephen Tomlin ${ }^{6}$
}

For numbered affiliations see end of article.

\section{Correspondence to}

Dr Asia Rashed, King's College London, 150 Stamford Street,

London SE1 9NH, UK; asia.rashed@kcl.ac.uk

Received 11 July 2013 Revised 4 July 2014 Accepted 24 September 2014 Published Online First 14 November 2014
CrossMark

To cite: Rashed AN, Hsia Y, Wilton L, et al. J Fam Plann Reprod Health Care 2015;41:216-222.

\begin{abstract}
Background Hormonal contraceptives are the most common method used worldwide by teenagers to prevent unwanted pregnancies. To date there are limited data about such use by teenagers in the UK. This study investigated trends and patterns of hormonal contraceptive prescribing to adolescents aged 12-18 years in UK primary care between 2002 and 2011
\end{abstract}

Methods A retrospective cohort study using the IMS Disease Analyzer database was conducted. All females aged $12-18$ years with $\geq 1$ prescription for a contraceptive drug between 1 January 2002 and 31 December 2011 were included. Annual prevalence of contraceptive drug prescribing was calculated, and indications for prescribing, and types of contraceptive drug prescribed, were examined.

Results In 2002, 13.7\% (6135/44 532) of female adolescents received prescriptions for hormonal contraceptives, compared to $19.0 \%$ (6597/34 676) in 2011. The majority of female adolescents [2002: 76.2\% (4676/6135); 2011: $65.7 \%$ (4334/6597)] received a contraceptive drug for 'contraceptive management'. The combined oral contraceptive (COC), 'progestogen+estrogen', was the most commonly prescribed. Although use of progestogen-only contraceptives was lower than $\mathrm{COCs}$, the number of patients who received desogestrel pills and etonogestrel implants increased during the study period; levonorgestrel pill use declined. Only one injectable progestogen, long-acting depot medroxyprogesterone acetate, was prescribed. Conclusions Use of hormonal contraceptives among adolescents increased between 2002 and 2011, and COC usage was dominant. The increasing use of hormonal contraceptives in adolescents, especially in younger adolescents, warrants further investigation, including research into the long-term safety of these medicines in this age group.

\section{Key message points}

- The use of hormonal contraceptives by female adolescents in the UK increased during the study period, 2002 to 2011.

- The contraceptive method most commonly prescribed to the study cohort was combined oral contraceptives.

- Research into the safety of long-term use of hormonal contraceptives by adolescents is needed.

\section{INTRODUCTION}

Adolescents are an age group at high risk of unintended pregnancy and the importance of safe sexual activity among adolescents has been recognised worldwide. ${ }^{12}$ In 2001, a report by United Nations Children's Fund (UNICEF) showed that in 1998 the UK had the highest teenage birth rate (30.8 per 1000 women aged 15-19 years) in Western Europe. ${ }^{2}$ The UK government therefore launched a 10-year national Teenage Pregnancy Strategy in $1999 .^{3}$ This national strategy aimed to halve the conception rate in those aged under 18 years by 2010 and establish a firm downward trend in those aged under 16 years, increase the proportion of teenage parents in education, training or employment to $60 \%$ by 2010 , and reduce their risk of long-term social exclusion. ${ }^{3}$ Following the launch of this strategy the conception rate for those aged under 18 years decreased by $34 \%$ between 1998 and 2011. ${ }^{4}$

A study from the USA demonstrated an approximately 23\% decline in birth rate for teenagers aged 15-19 years between 1995 and 2002. ${ }^{5}$ The authors stated that the decline of teenage pregnancy may be attributed to the improvement of contra- 
ceptive use in the USA. ${ }^{5}$ Though injectable hormonal contraceptives [e.g. depot medroxyprogesterone acetate injection (DMPA)] were considered among the most effective contraceptives, oral hormonal contraceptives were preferred by most female adolescents due to their effectiveness and ease of use. ${ }^{67}$

Patterns in the prescribing of combined hormonal contraceptives have changed over time (e.g. with the introduction of newer progestogens) ${ }^{8}$ but there is controversy regarding the risk of venous thromboembolism (VTE) with the different generations of combined pills. ${ }^{9-13}$ In January 2013, the Pharmacovigilance Assessment Committee (PRAC) at the European Medicine Agency (EMA) was asked by France to review the safety of the third- and fourth-generation combined oral hormonal contraceptives (COCs) due to concerns of a higher risk of VTE with these pills compared to first- and second-generation pills. ${ }^{14}$ The PRAC completed its report in October 2013 and concluded that the benefits of all combined hormonal contraceptives in preventing unwanted pregnancy outweigh their risk of VTE. ${ }^{15}$

A study conducted in UK, using the General Practice Research Database (GPRD) to investigate the level of combined contraceptive pills prescribed to women aged less than 16 years in general practice in $1997,{ }^{16}$ showed that only $4.2 \%$ of teenagers aged $13-15$ years received combined pills that year. The authors stated that the usage of the combined pill was low, considering that an estimated one-third of women aged less than 16 years were sexually active. They also stated that the low level of use of the combined pill may partially explain the high teenage birth rate in the UK compared to Western Europe. ${ }^{16}$ However, this study only investigated combined contraceptive pill use in 1 year, so it did not demonstrate the trends of contraceptive drug prescribing in female adolescents.

Despite the reduction of teenage pregnancy rates following the introduction of the UK government's Strategy on Teenage Pregnancy, ${ }^{3}$ the UK still has the highest rate of teenage pregnancy in Western Europe and so further reduction is needed for it to be on a comparable level with that of other Western European countries. ${ }^{17}$ Oral contraceptives are the most common contraception method used by female teenagers, so information about prescribing practices is necessary to prioritise further research into the use and long-term safety of hormonal contraceptive in this particular patient population. Hence, a cohort study based on a primary care health records database was conducted to investigate the current prescribing patterns of systemic hormonal contraceptives among a cohort of female teenagers aged 12-18 years between 2002 and 2011.

\section{METHODS}

\section{Study design}

A descriptive cohort study was conducted using the IMS Disease Analyzer (IMS DA) to investigate the prescribing trends and patterns of hormonal contraceptives, indications for prescribing and the type of hormonal contraceptives drug used in female adolescents in UK primary care.

\section{Data source}

IMS DA contains anonymised computerised information systematically recorded by UK general practitioners (GPs). This database contains drug prescriptions, diagnoses and demographic data directly obtained from GPs' computers. The data are derived from electronic health records in the GP practices via standardised interfaces and provide daily routine information on patients' diseases and therapies. A practice transmits patient data stored in their GPs' computers to IMS DA on a monthly basis, after the data are encrypted for data protection. Prescribed drugs are coded based on the Anatomical Therapeutic Chemical (ATC) classification issued by the European Pharmaceutical Market Research Association. ${ }^{18}$ Diagnoses are coded to the International Classification of Disease (ICD) version 10 codes. $^{19}$ Quality of the data is continuously monitored by IMS based on a number of quality criteria (e.g. completeness of documentation, linkage of diagnoses and prescriptions). The validity of IMS DA data has been described previously. ${ }^{20}$ The database has been widely used in paediatric pharmaco-epidemiological studies in recent years. $^{21-23}$

Data obtained from the database are anonymous, thus ethics committee approval was not needed for this study.

\section{Study population}

The study population comprised all females in IMS DA aged 12-18 years who had at least one prescription for a contraceptive drug (ATC code: G03A) between 1 January 2002 and 31 December 2011.

\section{Study outcomes}

Annual prevalence of contraceptive prescribing was calculated by counting all patients with at least one contraceptive prescription in a particular year, divided by the total number of female individuals in the IMS DA in that year. Annual prevalence of contraceptive drug prescribing was also calculated by age group, defined as those aged 12-15 years and those aged 16-18 years in the relevant year, and expressed as a percentage. Indications for prescribing hormonal contraceptives and the different types of hormonal contraceptives were examined in this population for 2002 and 2011.

The prevalence was calculated for each year for both age ranges, but we have presented the prevalence for 2002 and 2011 only, to show the trends over this 10 -year period.

\section{Statistical analysis}

Statistical analyses were performed using SAS software V.9.2 (SAS Institute, Cary, NC, USA). Absolute and 
Table 1 Characteristics of study subjects in 2002 and 2011, by age group

\begin{tabular}{|c|c|c|c|c|}
\hline \multirow[b]{2}{*}{ Characteristics } & \multicolumn{2}{|l|}{2002} & \multicolumn{2}{|l|}{2011} \\
\hline & Aged $12-15$ years & Aged $16-18$ years & Aged $12-15$ years & Aged $16-18$ years \\
\hline Total number of patients & 23714 & 20818 & 18414 & 16262 \\
\hline Number of patients with hormonal contraceptive prescription & 794 & 5341 & 968 & 5629 \\
\hline Average number of prescriptions per patient per year* & 2.0 & 2.2 & 2.2 & 2.4 \\
\hline Prevalence of prescribing $(95 \% \mathrm{Cl})$ & $3.3(3.1-3.6)$ & $25.7(25.0-26.3)$ & $5.2(4.9-5.5)$ & $34.6(33.7-35.5)$ \\
\hline
\end{tabular}

${ }^{*}$ Duration of each prescription is 6 months in line with clinical practice in the UK.

$\mathrm{Cl}$, confidence interval.

relative frequencies for contraceptive use by age group and year were calculated. Annual and age-specific prevalence of contraceptive prescribing was calculated using Poisson distribution with a $95 \%$ confidence interval $(\mathrm{CI})$.

\section{RESULTS}

In total, 44532 female adolescents aged 12-18 years were identified in the database in 2002 and 34676 in 2011. In 2002, $13.7 \%$ of the female adolescents $(n=6135 / 44532)$ received prescriptions for hormonal contraceptives, compared with $19.0 \% \quad(n=6597 /$ 34676 ) in 2011. Table 1 shows the patient characteristics and prevalence for prescribing hormonal contraceptives by age group in 2002 and 2011. Figure 1 shows the annual prevalence of contraceptive prescribing by age group between 2002 and 2011. The prevalence of contraceptive prescribing was higher in ages 16-18 years compared to ages 12-15 years $(p<0.001)$. In the $12-15$ years age group the annual prevalence of prescribing increased from 3.3\% $(95 \%$ CI $3.1-3.6 \%)$ in 2002 to $5.2 \%$ (95\% CI $4.9-5.5 \%)$ in 2011. The annual prevalence of prescribing to those aged 16-18 years increased from 25.7\% (95\% CI $25.0-26.3$ ) in 2002 to $34.6 \%$ (95\% CI $33.7-35.5$ ) in 2011.

Table 2 shows the indications for prescribing hormonal contraceptives to female adolescents, by age group. The main indication for prescribing hormonal contraceptive drugs was 'contraceptive management'. In 2002, overall, $76.2 \%(n=4676 / 6135)$ of patients received hormonal contraceptives for this indication compared to $65.7 \%(n=4334 / 6597)$ in 2011 . The second most common indication for prescribing these contraceptive drugs in this study population was the treatment of 'excessive, frequent and irregular menstruation'. The number of female adolescents who received contraceptives for the treatment of acne or urinary system disorders was low. For $8.5-15 \%$ of patients the indication was not specified.

Table 3 shows the most commonly prescribed hormonal contraceptive formulations by age groups and by year. The COC group 'progestogens+estrogens' were the dominant contraceptives used over the study period, of which the combination of 'ethinylestradiol +levonorgestrel' was the most frequently prescribed

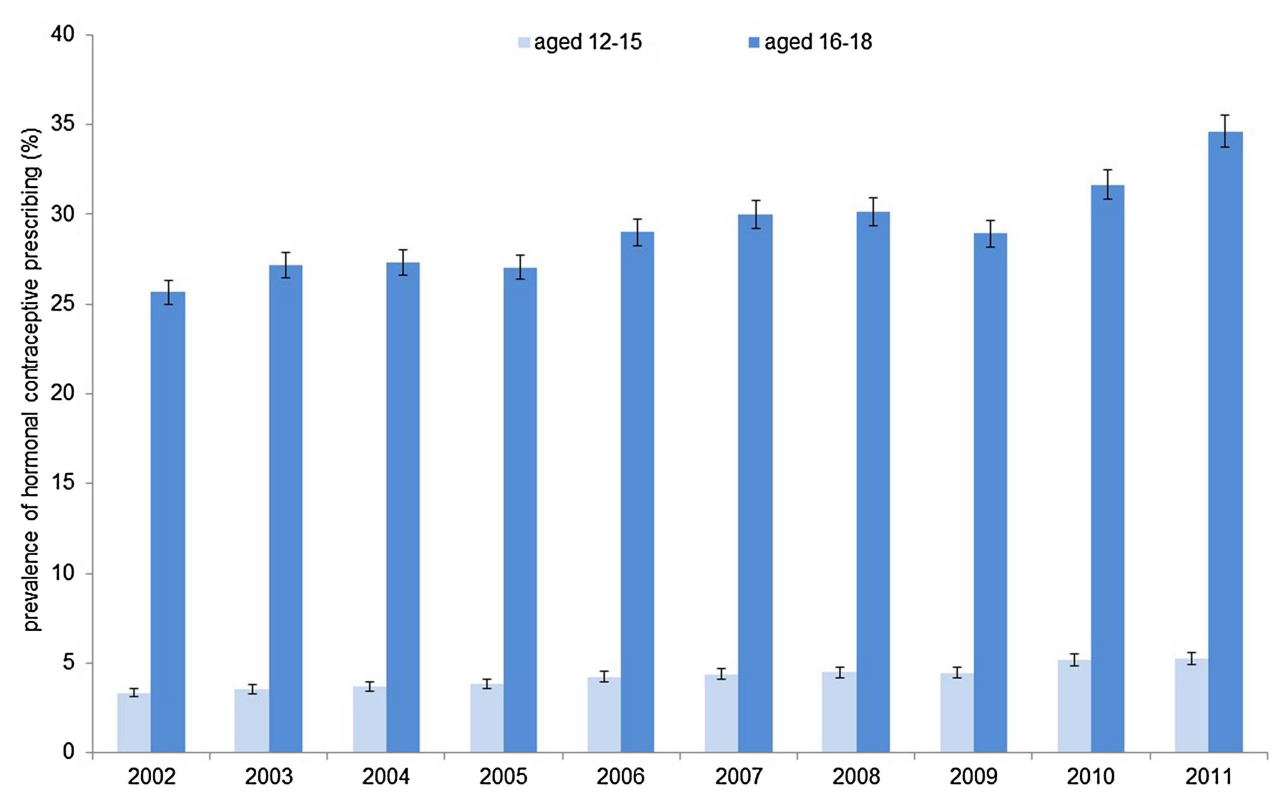

Figure 1 Age-specific prevalence of contraceptive drug prescribing by year (with $95 \%$ confidence intervals) in general practice in the UK, 2002-2011. 
Table 2 Recorded diagnosis for contraceptive prescribing amongst female adolescents in 2002 and 2011, by age group

\begin{tabular}{|c|c|c|c|c|}
\hline & $\begin{array}{l}\text { Aged } \\
12-15 \text { years }\end{array}$ & $\begin{array}{l}\text { Aged } \\
12-15 \text { years }\end{array}$ & $\begin{array}{l}\text { Aged } \\
16-18 \text { years }\end{array}$ & $\begin{array}{l}\text { Aged } \\
16-18 \text { years }\end{array}$ \\
\hline Diagnosis (ICD 10) & Patients $[n(\%)]$ & Patients $[n(\%)]$ & Patients [n (\%)] & Patients $[n(\%)]$ \\
\hline$\overline{\text { Contraceptive management (Z30) }}$ & $450(56.7)$ & $397(41.0)$ & $4226(79.1)$ & $3937(69.9)$ \\
\hline Excessive, frequent and irregular menstruation (N92) & $120(15.1)$ & $200(20.7)$ & $218(4.1)$ & $459(8.2)$ \\
\hline $\begin{array}{l}\text { Pain and other conditions associated with female genital organs and } \\
\text { menstrual cycle (N94) }\end{array}$ & $71(8.9)$ & $107(11.1)$ & $167(3.1)$ & $325(5.8)$ \\
\hline Personal history of other diseases and conditions (Z87) & $40 \quad(5.0)$ & $78(8.1)$ & $155(2.9)$ & $245(4.4)$ \\
\hline Other disorders of urinary system (N39) & $6(0.8)$ & $12(1.2)$ & $26(0.5)$ & $80(1.4)$ \\
\hline Acne (L70) & $3(0.4)$ & $30(3.1)$ & $13(0.2)$ & $105(1.9)$ \\
\hline Patients without recorded diagnosis for contraceptive prescription & $104(13.1)$ & $144(14.9)$ & $536(10.0)$ & 478 (8.5) \\
\hline
\end{tabular}

ICD, International Classification of Disease; $N$, number of patients with contraceptive prescription.

in both age groups; $12-15$ years and 16-18 years. Although the usage of progestogen-only contraception was lower compared to COCs, the numbers of patients who received desogestrel and etonogestrel steadily increased in both age groups during the study period, but for levonorgestrel, they decreased. DMPA was the only parenteral progestogen used in our study subjects. There were no prescriptions for vaginal or transdermal contraceptives.

\section{DISCUSSION}

This study investigated the contraceptive prescribing trends and prescription patterns for female adolescents in the UK primary care setting. The most commonly prescribed formulation was combined oral hormonal contraceptives. This is consistent with the study conducted by Sturkenboom et al. ${ }^{24}$ in three European countries, which found that, in the UK, oral contraceptives were among the top five drugs prescribed for the genitourinary system.

Our study showed that there was an increase in the prevalence of prescribing hormonal contraceptives by GPs to females aged 12-18 years between 2002 and 2011, and there was an increase in the prescribing of progestogen-only contraceptives (desogestrel, etonogestrel) to females aged 12-18 years during the study period. This might partly explain the decrease in conception rate in women under 18 years as published by the Office for National Statistics in the UK. ${ }^{4}$ Also, the increased prescribing of hormonal contraceptives might indicate that there has been an increased awareness of sexual health and contraception among female adolescents following the introduction of the UK government's Teenage Pregnancy Strategy. ${ }^{3}$ Contraceptive management was the main indication for prescribing hormonal contraceptives to our study subjects.

Table 3 Use of different formulations of hormonal contraceptives for female adolescents aged 12-18 years in general practices in the UK

\begin{tabular}{|c|c|c|c|c|}
\hline \multirow[b]{2}{*}{ Formulations* } & \multicolumn{2}{|c|}{$\begin{array}{l}\text { Aged } 12-15 \text { years } \\
\text { Patients [n (\%)] }\end{array}$} & \multicolumn{2}{|c|}{$\begin{array}{l}\text { Aged } 16-18 \text { years } \\
\text { Patients }[n(\%)]\end{array}$} \\
\hline & 2002 & 2011 & 2002 & 2011 \\
\hline Total number of patients with hormonal contraceptive prescriptions & 794 & 968 & 5341 & 5629 \\
\hline \multicolumn{5}{|l|}{ Combined oral contraceptive (progestogen+estrogen): } \\
\hline Ethinylestradiol+levonorgestrel & $492(62.0)$ & $560(57.9)$ & $3385(63.4)$ & $3053(54.2)$ \\
\hline Ethinylestradiol+drospirenone & $13(1.6)$ & $62(6.4)$ & $68(1.3)$ & $566(10.1)$ \\
\hline Ethinylestradiol+norgestimate & 68 (8.6) & $59(6.1)$ & $615(11.5)$ & $436(7.7)$ \\
\hline Ethinylestradiol+norethisterone & $101(12.7)$ & $75(7.7)$ & $437 \quad(8.2)$ & $309(5.5)$ \\
\hline Ethinylestradiol+desogestrel & $28(3.5)$ & $47 \quad(4.9)$ & $259(4.8)$ & $345(6.1)$ \\
\hline Ethinylestradiol+gestodene & $23(2.9)$ & $16(1.7)$ & $199(3.7)$ & $125(2.2)$ \\
\hline \multicolumn{5}{|l|}{ Progestogen-only contraceptive: } \\
\hline Desogestrel & $0(0.0)$ & $100(10.3)$ & $0(0.0)$ & $767(13.6)$ \\
\hline Etonogestrel (implant) & $2(0.3)$ & $91(9.4)$ & $19(0.4)$ & $380(6.8)$ \\
\hline Levonorgestrel & $155(19.5)$ & 64 (6.6) & $740(13.9)$ & $308(5.5)$ \\
\hline Depot medroxyprogesterone acetate & $37(4.7)$ & $57 \quad(5.9)$ & $496 \quad(9.3)$ & 474 (8.4) \\
\hline
\end{tabular}

Data are presented as number and percentage of patients [ $n(\%)]$. The percentages in the table do not add up to $100 \%$ as a patient might be prescribed more than one formulation of contraceptive during a year.

*All formulations presented in the table are oral form unless otherwise specified. 
The increased use of progestogen-only contraceptives might be because they do not increase the VTE risk significantly compared to COCs. ${ }^{25}$ Conversely, the prescriptions of levonorgestrel decreased over the years, particularly in the younger age group. One possible explanation might be related to the potential increased efficacy of the desogestrel progestogen-only pill (POP) with its 12-hour rule for missed pills, compared to the levonogestrel POP with the need for greater compliance due to loss of efficacy if a pill is taken more than 3 hours late. ${ }^{26}$ Levonorgestrel is also prescribed as an emergency hormonal contraceptive in the $\mathrm{UK},{ }^{27}$ thus the amount prescribed might suggest that it was prescribed for that purpose, though this is not specified in the database. Another explanation might be that since 2001 emergency hormonal contraceptives can be obtained from community pharmacies in the UK by those aged over 16 years, ${ }^{28}$ thus their data in the GP records may have decreased.

Our study has shown that hormonal contraception prescribing steadily increased between 2002 and 2011. The usage of hormonal contraception was higher in girls aged 16-18 years compared to girls aged $12-15$ years. This is consistent with a recent retrospective study from Germany that investigated the prescribing trends of contraceptives in adolescent girls in 2007 and 2011. This study also found a significant increase in contraceptive usage among this population $^{29}$ that may indicate that the older teenage girls became more concerned about unwanted pregnancy. Another possible reason for less contraceptive prescribing to the younger age group could be that a lower proportion of them were sexually active. ${ }^{30} 31$ However, previous studies have reported that concerns about contraceptive side effects might lead younger girls to discontinue or avoid using contraceptive pills, which could increase the risk of unintended pregnancy. 73233

VTE has been associated with the use of combined hormonal contraceptives. ${ }^{31}$ A recent review reported that COCs containing desogestrel, gestodene or drospirenone, in combination with ethinylestradiol, are associated with a higher risk of VTE compared with other contraceptives. ${ }^{34}$ There remains a debate about the VTE risk associated with the use of contraceptive pills but we cannot comment on this potential association in female adolescents, as it was not possible to investigate this in our current study. Further research is needed to investigate this association in this age group.

A range of contraceptive formulations was prescribed to our study population. The most commonly prescribed preparation was the COC containing ethinylestradiol+levonorgestrel. This is consistent with the results from studies in adult women. ${ }^{31}$ The use of DMPA, which was the only injectable contraceptive used by our study population, was very low over the study period. This may be because DMPA has been associated with bone mineral density reduction in women aged $12-18$ years. ${ }^{3}$ Whilst some data suggest that there may be substantial increases in bone mass after DMPA is stopped, ${ }^{7}$ information on long-term follow up after discontinuation of use in those women is still lacking.

\section{Study strengths and limitations}

To our knowledge, this is the first population-based study to investigate prescribing patterns of hormonal contraceptives to female adolescents in the UK in the general practice setting. Our study has provided comprehensive information on the prescribing trends and patterns of hormonal contraceptives to female adolescents from 2002 to 2011. Also, the database used in this study provided data to enable us also to investigate the indications for prescribing these contraceptives to teenagers and the formulations used.

However, this study has several limitations. First, the database only contains prescriptions issued in the primary care setting, and excludes those prescribed or supplied from family planning clinics or hospitals. However, the number of prescriptions from these sources is expected to be small because the majority of contraceptive prescriptions for adolescents are issued by GPs. ${ }^{36}$

Second, the IMS DA does not contain data on ethnicity and socioeconomic status, thus their impact on contraceptive use in female adolescents could not be investigated. Finally, there was no information in the database on compliance and adherence to prescriptions issued. This is a general limitation of many health care databases as they contain information on prescriptions issued but do not contain information on whether the prescription was dispensed, nor whether it was taken.

\section{Future research}

The use of hormonal contraceptives in female adolescents increased from 2002 to 2011, but there is little, if any, information on the long-term safety of these drugs in adolescents, in particular for girls aged under 16 years. The UK continues to have the highest teenage pregnancy rate in Europe. As younger adolescent girls who are sexually active were found to be three times more likely to become pregnant than those who have sexual intercourse for the first time aged over 16 years, ${ }^{37}$ there is a need to prioritise research into contraceptive drug use in female adolescents, especially for those aged under 16 years. The recent PRAC review concluded that the benefits of reducing unwanted pregnancy outweigh the risk of VTE for all hormonal contraceptives, but as knowledge on the long-term safety of contraceptive use in adolescents is limited, continued monitoring of their use in this group is warranted. 


\section{CONCLUSIONS}

We found an increase in the prescribing of hormonal contraceptives to female adolescents in the UK from 2002 to 2011 for both the $12-15$ and 16-18 years age ranges. As there is little, if any, information about the long-term safety of the use of hormonal contraceptives in adolescents, further research is needed.

\section{Author affiliations}

${ }^{1}$ Research Associate, Institute of Pharmaceutical Science, King's College London, King's Health Partners, London and Honorary Research Pharmacist, Evelina London Children's Hospital, Guy's \& St Thomas' NHS Foundation Trust, King's Health Partners, London, UK

${ }^{2}$ Research Fellow, University College London, School of Pharmacy, London, UK and Research Fellow, Department of Pharmacology and Pharmacy, Li Ka Shing Faculty of Medicine, Centre for Safe Medication Practice and Research, The University of Hong Kong, Hong Kong, China

${ }^{3}$ Honorary Research Consultant, University College

London, School of Pharmacy, London, UK

${ }^{4}$ Gynaecologist, Department of Gynaecology,

University Hospital of Giessen and Marburg GmbH, Marburg, Germany

${ }^{5}$ Research Consultant, IMS HEALTH Epidemiology, Frankfurt, Germany

${ }^{6}$ Honorary Clinical Reader, Institute of Pharmaceutical Science, King's College London, King's Health Partners, London and Consultant Pharmacist, Evelina London Children's Hospital, Guy's \& St Thomas' NHS Foundation Trust, King's Health Partners, London, UK

\section{Competing interests None.}

Provenance and peer review Not commissioned; externally peer reviewed.

\section{REFERENCES}

1 Finer LB, Henshaw SK. Disparities in rates of unintended pregnancy in the United States, 1994 and 2001. Perspect Sex Reprod Health 2006;38:90-96.

2 UNICEF. A League Table of Teenage Births in Rich Nations. Innocenti Report Card No. 3. Florence, Italy: UNICEF Innocenti Research Centre, July 2001. http://www.unicef-irc. org/publications/pdf/repcard3e.pdf [accessed 30 January 2014]

3 Department of Education. Teenage Pregnancy Strategy: Beyond 2010. https://www.education.gov.uk/publications/standard/ publicationDetail/Page1/DCSF-00224-2010 [accessed 30 January 2014].

4 Office for National Statistics. Conceptions in England and Wales, 2011. 2013. http://www.ons.gov.uk/ons/dcp171778_ 301080.pdf [accessed 15 January 2014].

5 Santelli JS, Lindberg LD, Finer LB, et al. Explaining recent declines in adolescent pregnancy in the United States: the contribution of abstinence and improved contraceptive use. Am J Public Health 2007;97:150-156.
6 Simon H, Zieve D. Birth control options for women - oral contraception and combination hormonal methods. 2012. http://umm.edu/health/medical/reports/articles/birth-controloptions-for-women [accessed 30 January 2014].

7 Greydanus DE, Patel DR, Rimsza ME. Contraception in the adolescent: an update. Pediatrics 2001;107:562-573.

8 Cerel-Suhl SL, Yeager BF. Update on oral contraceptive pills. Am Fam Physician 1999;60:2073-2084.

9 World Health Organization. Venous thromboembolic disease and combined oral contraceptives: results of international multicentre case-control study. World Health Organization Collaborative Study of Cardiovascular Disease and Steroid Hormone Contraception. Lancet 1995;346:1575-1582.

10 Bloemenkamp KW, Rosendaal FR, Helmerhorst FM, et al. Enhancement by factor V Leiden mutation of risk of deep-vein thrombosis associated with oral contraceptives containing a third-generation progestagen. Lancet 1995;346: 1593-1596.

11 Bitzer J, Amy JJ, Beerthuizen R, et al. Statement on combined hormonal contraceptives containing third- or fourth-generation progestogens or cyproterone acetate, and the associated risk of thromboembolism. J Fam Plann Reprod Health Care 2013;39:156-159.

12 Lewis MA, MacRae KD, Kühl-Habich D, et al. The differential risk of oral contraceptives: the impact of full exposure history. Hum Reprod 1999;14:1493-1499.

13 Dinger JC, Heinemann LAJ, Kühl-Habich D. The safety of a drospirenone-containing oral contraceptive: final results from the European Active Surveillance study on oral contraceptives based on 142,475 women years of observation. Contraception 2007;75:344-354.

14 European Medicines Agency. European Medicines Agency to review third- and fourth-generation combined oral contraceptives. 28 January 2013. http://www.ema.europa.eu/ ema/index.jsp?curl=pages/news_and_events/news/2013/01/ news_detail_001700.jsp\&mid=WC0b01ac058004d5c1 [accessed 30 January 2014].

15 European Medicines Agency. PRAC confirms that the benefits of all combined hormonal contraceptives (CHCs) continue to outweigh risks. 11 October 2013. http://www.ema.europa.eu/ docs/en_GB/document_library/Press_release/2013/10/ WC500151960.pdf [accessed 30 January 2014].

16 Rowlands S, Devalia H, Lawrenson R. Use of the combined oral contraceptive pill by under 16s. J Fam Plann Reprod Health Care 2001;27:17-19.

17 Hadley A, Evans DT. Teenage pregnancy and sexual health. Nurs Times 2013;109:22-27.

18 European Pharmaceutical Market Research Association: ATC Anatomical Classification. http://www.ephmra.org/ Anatomical-Classification [accessed 30 January 2014].

19 International Classification of Diseases Version 10. 2010. http:// www.who.int/classifications/icd/en/ [accessed 30 January 2014].

20 Becher H, Kostev K, Schröder-Bernhardi D. Validity and representativeness of the Disease Analyzer patient database for use in pharmacoepidemiological and pharmacoeconomic studies. Int J Clin Pharm Therap 2009;47:617-626.

21 Hsia Y, Neubert AC, Rani F, et al. An increase in the prevalence of type 1 and 2 diabetes in children and adolescents: results from prescription data from a UK general practice database. Br J Clin Pharmacol 2009;67:242-249.

22 Hsia Y, Neubert A, Sturkenboom MC, et al. Comparison of antiepileptic drug prescribing in children in three European countries. Epilepsia 2010;51:789-796. 


\section{Article}

23 Neubert A, Verhamme K, Murray ML, et al. The prescribing of analgesics and non-steroidal anti-inflammatory drugs in paediatric primary care in the UK, Italy and the Netherlands. Pharmacol Res 2010;62:243-248.

24 Sturkenboom MC, Verhamme KM, Nicolosi A, et al. Drug use in children: cohort study in three European countries. BMJ 2008;337:a2245.

25 Rott H. Thrombotic risks of oral contraceptives. Curr Opin Obstet Gynecol 2012;24:235-234.

26 Faculty of Sexual \& Reproductive Healthcare Clinical Effectiveness Unit. Progestogen-only Pills. November 2008. http://www.fsrh.org/pdfs/CEUGuidanceProgestogenOnlyPill09. pdf [accessed 2 July 2014].

27 Faculty of Sexual \& Reproductive Healthcare Clinical Effectiveness Unit. Contraceptive Choices for Young People. March 2010. http://www.fsrh.org/pdfs/ceuGuidanceYoung People2010.pdf [accessed 26 January 2014].

28 Anderson C, Blenkinsopp A. Community pharmacy supply of emergency hormonal contraception: a structured literature review of international evidence. Hum Reprod 2006;21:272-284.

29 Ziller M, Rashed A, Ziller V, et al. The prescribing of contraceptives for adolescents in German gynocological practices in 2007 and 2011: a retrospective database analysis. J Pediatr Adolesc Gynecol 2013;26:261-264.

30 Holcombe E, Carrier D, Manlove J, et al. Contraceptive use patterns across teens' sexual relationships. Trend Child Fact Sheet. February 2008. http://www.childtrends.org/wp-content/
uploads/2013/01/Teen-Contraceptive-Patterns.pdf [accessed 30 January 2014].

31 Rowen TS, James SF, Michael EL, et al. Contraceptive usage patterns in North American medical students. Contraception 2011;83:459-465.

32 Coles MS, Makino KK, Stanwood NL. Contraceptive experiences among adolescents who experience unintended birth. Contraception 2011;84:578-584.

33 Hickson SS, Miles KL, McDonnell BJ, et al. Use of the oral contraceptive pill is associated with increased large artery stiffness in young women: the ENIGMA study. J Hypertens 2011;29:1155-1159.

34 Stegeman BH, de Bastos M, Rosendaal FR, et al. Different combined oral contraceptives and the risk of venous thrombosis: systematic review and network meta-analysis. BMJ 2013;347:f5298.

35 Cromer BA, Stager M, Bonny A, et al. Depot medroxyprogesterone acetate, oral contraceptives and bone mineral density in a cohort of adolescent girls. J Adolesc Health 2004;35:434-441.

36 National Services Scotland. Scotland's Sexual Health Information. 2009. http://www.documents.hps.scot.nhs.uk/ bbvsti/sti/publications/sshi-2009-11-24.pdf [accessed 30 January 2014].

37 Wellings K, Nanchahal K, Macdowall W, et al. Sexual health in Britain: early heterosexual experience. Lancet 2001;358: 1834-1850. 